\title{
Investigations of Damping Capacity and Fretting Wear Behaviour of AlTiN Coated Friction Damper
}

\section{Maqusud Alam ${ }^{1 *}$; Kutubuddin Ansari² ${ }^{\text {; Sunil Kumar Sharma }}{ }^{3}$}

${ }^{1}$ Department of Mechanical Engineering, Aligarh Muslim University, Aligarh, 202002, India ${ }^{2}$ Department of Geoinformation Engineering, Sejong University, Seoul, 05006, South Korea ${ }^{3}$ College of Computer and Information Sciences, Majmaah University, Majmaah- 11952, Saudi Arabia

\section{Email: maqusudmce@gmail.com; kdansarix@gmail.com; s.sharma@mu.edu.sa}

\begin{abstract}
The concept of friction damper is widespread technique and used to reduce the structural vibrations in many industrial applications. These friction dampers are generally coated with low wear rate materials to reduce the fretting wear. This paper investigates the use of physical vapor deposition (PVD) nitride based AlTiN coating material applied over the stainless steel friction damper to enhance the damping capacity and to reduce the fretting wear. A friction test rig has been developed to measure the dynamic hysteresis characteristics of friction damper at high temperature $\left(700{ }^{\circ} \mathrm{C}\right)$. The damping capacity and fretting wear analysis is carried out at room temperature, $300{ }^{\circ} \mathrm{C}$ and $600{ }^{\circ} \mathrm{C}$. The force versus displacment characterisitcs curve is used to predict the damping capacity and fretting wear analysis is carried out at microscopic level for the comparision. It is observed that at room temperature AlTiN coated friction damper has not much influence to improve the damping capacity and to reduce the fretting-wear. However, at high temperature it has better damping capacity and less wear in comparision to uncoated friction damper. Wear behaviour in coated and uncoated damper is different at room temperature and at elevated temperature.
\end{abstract}

KEYWORDS: Friction damper, Coating, Damping capacity, Fretting-wear

\section{INTRODUCTION}

Mechanical structures with contact interfaces appear in many engineering applications. There are different categories of friction contacts. In some cases, frictional contact is intentionally introduced as in case of frictional dampers between the blades of the gas turbines. However, frictional contact can be a unwanted secondary effect as in bolted or riveted joints [1]. Dry friction dampers are widely applied in the structural designs to reduce the vibrational stress effectively. Damper transmits a load through a 
friction contact that dissipates energy once slip pheonomenon occurs. The friction forces generated among these contact zones play a crucial role in determining the dynamic behaviour of the structure $[2,3]$. In addition, it is reported that the frictional dampers which causes the vibration reduction involves the stick- slip phenomenon accompanied by fretting-wear [4]. Hence the fretting wear mechanism in such dampers is an important aspect to investigate.

Fretting wear occurs in any structural element when it is subjected to small relative displacement due to the normal contact load [5]. In addtion, there are chances of crack initation at damage surface affecting the fatigue strength of structural components. To reduce the fretting-wear, damping elements are generally coated with low wear rate coating materials. However, low wear rate coating materials are often exhibit low friction coefficient. Friction between the contact surfaces plays the vital role in the energy dissipation and vibration damping in dry friction damping structures [3]. Application of low wear rate material over the frictional dampers reduces energy dissipation and the vibration damping. Thus it is interesting to investigate different coating materials featuring high damping capacity and low fretting-wear.

Many researchers have studied the effect of friction damper to reduce the vibration stresses in structural components. Effect of friction damper in a bladed disc assembly of gas turbine has been investigated in [6,7] whereas in gas turbine airfoils has been studied in [8] to limit and occurance of wear and early failures. They concluded that friction damper is an effective way to dissipate the vibration energy. Many researchers have also investigated the fretting wear behaviour in structural components. Lavella et al.[9] have analyzed the fretting wear in turbomachinary at the blade tip interfaces with and without T-800 (cobalt-chromium-molybdenum) spray coating at high temperature. It has been noted that coated surface shows steady value of friction co-efficient, stiffness and contact parameters as compared to uncoated surface. The uncoated surface show a layer of oxides that is formed and broken continuously during the wear process. Botto et al.[10] have studied the wear behaviour of two types of cobalt based coating with different percentage of alumina content and deposition method. It has been seen that that co-efficient of friction is not a monotonic function of temperature and it's value is maximum at around $300{ }^{\circ} \mathrm{C}$. Higher elasticity modulus coating shows lower contact stiffness and Contact stifness is effected by temperature. In recent years, researchers have developed new materials and methods to improve the performance of coatings. The tribological behaviour of coating is affected by several parameters such as (i) contact conditions-normal load, relative speed, surface morphology, (ii) environmental conditions - temperature, gases, lubrication and (iii) contact materials, in terms of mechanical and chemical properties. Contact parameters such as coefficient of friction and wear rate cannot be accurately predicted solely through theoretical analysis. Due to the complex tribological contact mechanisms an experimental investigations are carried out to evaluate the wear behaviour of nitride-based AlTiN coatings. The tribological behaviour of physical vapor deposition (PVD) nitride coating AlTiN has been studied in [11] by means of ball-on-disk rig at room temperature. Four differnt PVD nitride based coatings TiN, TiAlN, AlTiN and CrAlN have been compared which were deposited on the cemented carbide by cathodic arc-evaporation technique. AlTiN and TiAlN has many advantages on other coating materials such as increased oxidation resistance at elevated temperatures and high hardness. AlTiN has found to be hard coating materials in comparision to TiAlN.

The aim of the present work is to develop a friction test rig. Which is used to measure the dynamic hysteresis characteristics of friction damper at high temperature $\left(700{ }^{\circ} \mathrm{C}\right)$. Furthermore, friction test rig is used to investigate the effect of AlTiN coating materials on fretting wear and damping capacity of friction damper at room temperature as well as at high temperature. Effort has been made to demonstrate the improved damping capacity and reduced fretting wear concurrently. The study is 
based on an integrated analysis of hysteresis loop with contact parameter- friction coefficient. The worn surfaces is analyzed by using optical microscope, surface profilometer and scanning electron microscopy (SEM) for various conditions.

\section{EXPERIMENTAL DEVICE AND PROCEDURES}

The test rig is used for measuring the dynamic hysteresis charateristics at very high temperature $\left(700{ }^{\circ} \mathrm{C}\right)$. which is developed by the authors based on the references $[12,13]$. The main concept of the test rig shown in Fig. 1 and in Fig. 2 is a unidirectional motion of a moving mass and specimen, excited by an electrodynamic shaker, against a static specimen. Two test specimens with a circular cross section, diameter $12 \mathrm{~mm}$ are made of stainless steel. One with cylindrical surface and the other with flat surface shape rubs against each other with a displacement of very low amplitude. The test rig keeps a flat surface with a cylindrical surface by means of constant normal load applied with a dead weight on the cylindrical surface. The flat suface was kept in movement by a vibrating beam in order to generate a sliding alternating motion of this surface on the cylindrical surface. Since the relative displacement of the specimen is in micro-scale, it is impossible to implement it using a general actuator. Therefore, the relative displacement was generated by using the resonance characteristics of the structure. The upper and lower holders for fixing the specimen have a mass and a structure connected to the load cell, respectively. The upper holder is directly connected to the mass and has a structure for maximizing heat dissipation. The lower holder is in point contact with the load cell and is balanced by the load in the vertical direction and the preload in the direction of the load cell. If the load cell and the lower holder are fixed, a moment may be generated by the acting load. In order to prevent damage to the load cell due to heat transfer at high temperature, the length of the lower holder should be long, but it is designed to be relatively short due to the limitation of the minimum distance of the laser distance sensor.

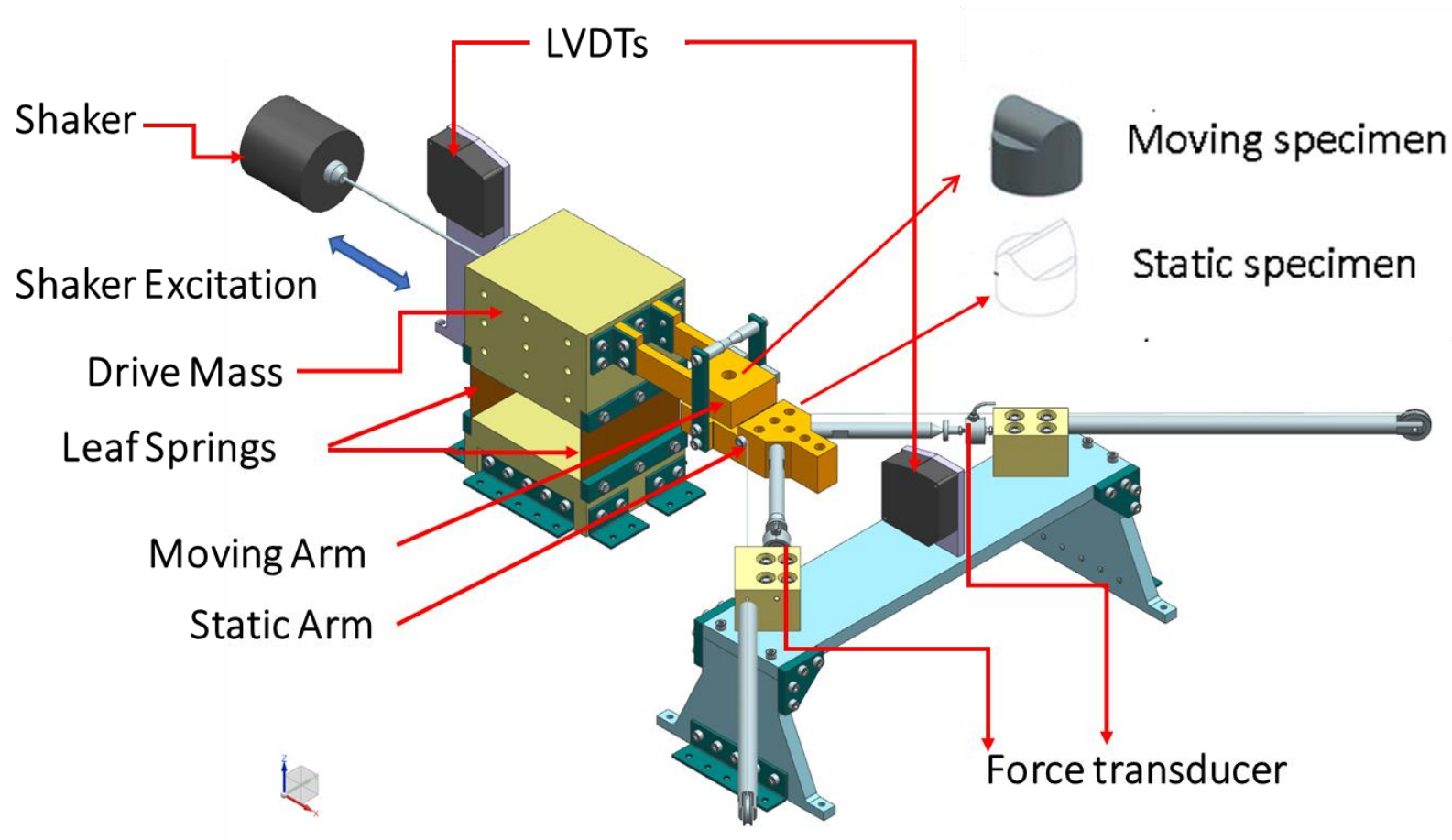

Fig.1. Schematic view of friction test rig 


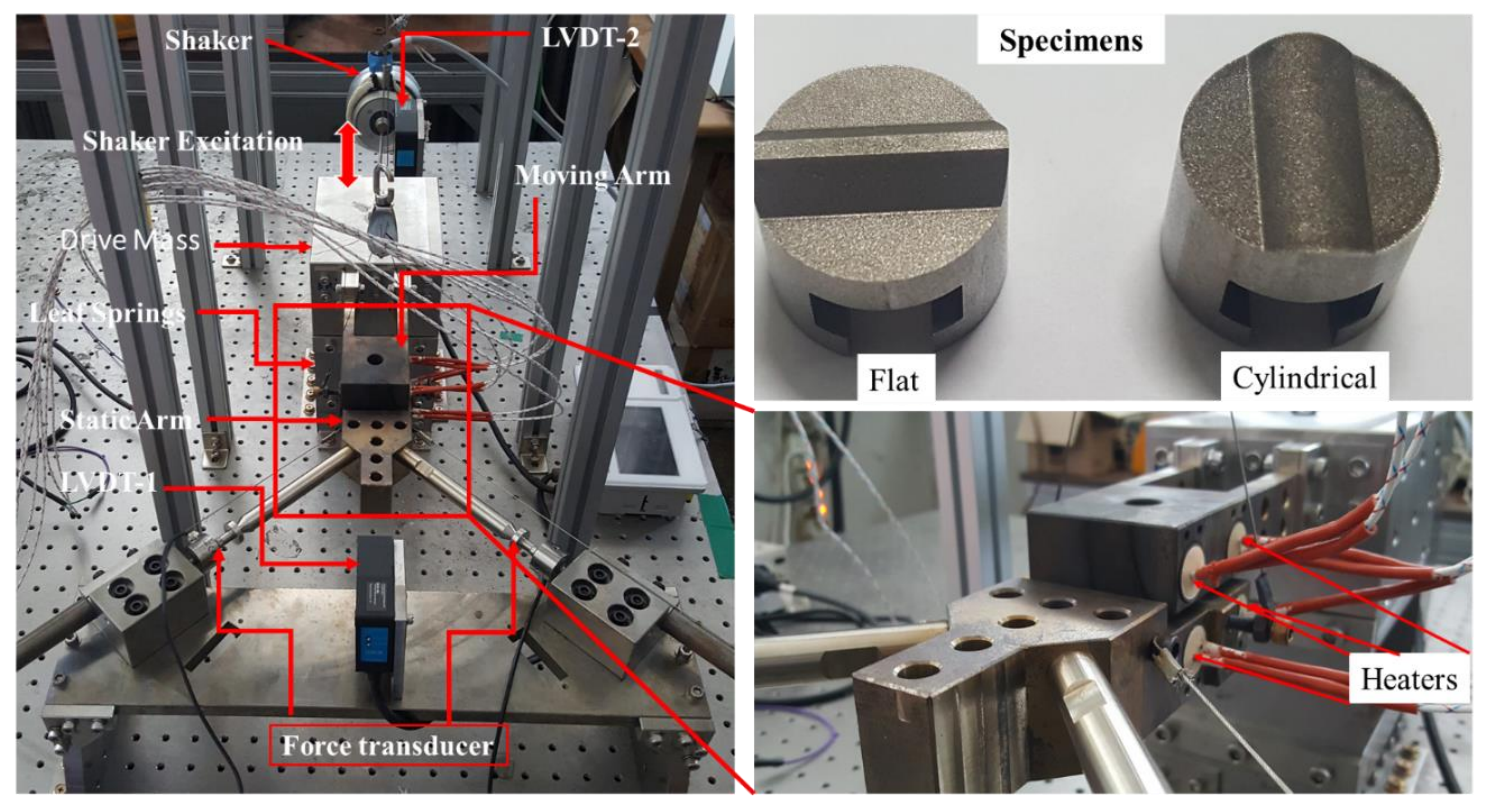

Fig.2. Overview of the experimental device and specimen.

A cartridge heater was used to conduct the friction test under high temperature conditions. Two cartridge heaters were used for each holder, and they were placed symmetrically so that the temperature could be uniformly transferred to the specimen. A contactless simultaneous measurement of the relative displacement between the two test specimens is achieved by two laser displacement sensors (LDVs). The transmitted friction forces are measured via three force transducers at the static side of the rig. A combination of the friction forces and the relative displacement for a given test configuration leads to the hysteresis loop in micro-slip and macroslip regions. A micro furnace can be fitted to the rig, allowing the testing of high-temperature materials for general applications, up to $700{ }^{\circ} \mathrm{C}$. The test rig allows an accurate extraction of the friction input parameters and has provided data for a large range of materials and operational conditions in a very short amount of time that can be used in a nonlinear dynamic analysis for a reliable prediction [13]. All the Experimental parameters, variables and the fixed conditions has been summarised in Table.1.

To measure the damping capacity hysteresis loop were continuously measured during the experiment. This loop was saved and stored at fixed interval of time for each case. The discription of the acquisition and control software can be found in [13], [14]. By the computing on the hysteresis loops was obtained the friction co-efficient, a discription of the used methology can be found in [13]. To ensure the repeatability of the test, three pairs of the friction specimens with the same parameters are measured for each experimental condition. The value of friction co-efficient was taken an average value for each case.

\section{RESULTS AND DISCUSSION}

Damping capacity and fretting-wear behaviour of AlTiN coated and uncoated friction damper has been investigated in this paper. Fig. 3 shows the comparisons of hysteresis loop i.e., diagram of the tangential force against the relative displacement recorded during the test of uncoated and coated specimen at room temperature, $300{ }^{\circ} \mathrm{C}$ and $600{ }^{\circ} \mathrm{C}$ respectively. The area of hysteresis loop represents 
the damping capacity. The more is the area under the hysteresis loop the more is the damping capacity of friction damper. From the Fig. 3(a) it is observed that damping capacity of coated specimen and uncoated specimen at room temperature is almost same. However, at $300{ }^{\circ} \mathrm{C}$ in Fig. $3\left(\right.$ b) and at $600{ }^{\circ} \mathrm{C}$ in Fig. 3(c) damping capacity's of coated specimen are better than the uncoated specimen. Fig. 4 sammarise the variation of friction coefficient with time at different temperature, which mainly depends on the nature of the surfaces. There are three main contributions to the friction coefficient, namely deformation of surface asperities, ploughing of wear particles and adhesion of contact surfaces. Therefore the coefficient of friction is not a simple material property but rather there is a sort of "memory" of the friction contact. There is a variation in friction coefficient with time at room temperature, $300{ }^{\circ} \mathrm{C}$, and $600{ }^{\circ} \mathrm{C}$ during experiment of coated and uncoated specimen as shown in Fig. 4(a), Fig. 4(b) and Fig. 4(c) respectively. Also, there is a monotonic decrease in the coefficient of friction with an increase of temperature due to the development of a protective oxide layer for this contact pair. With the increase in the temperature, this layer becomes more stable contributing to the lower interfacial shear strength at the contact interface. It leads to lowering the coefficient of friction. The experiment carried out shows the good agreement with the physcial phenomena.
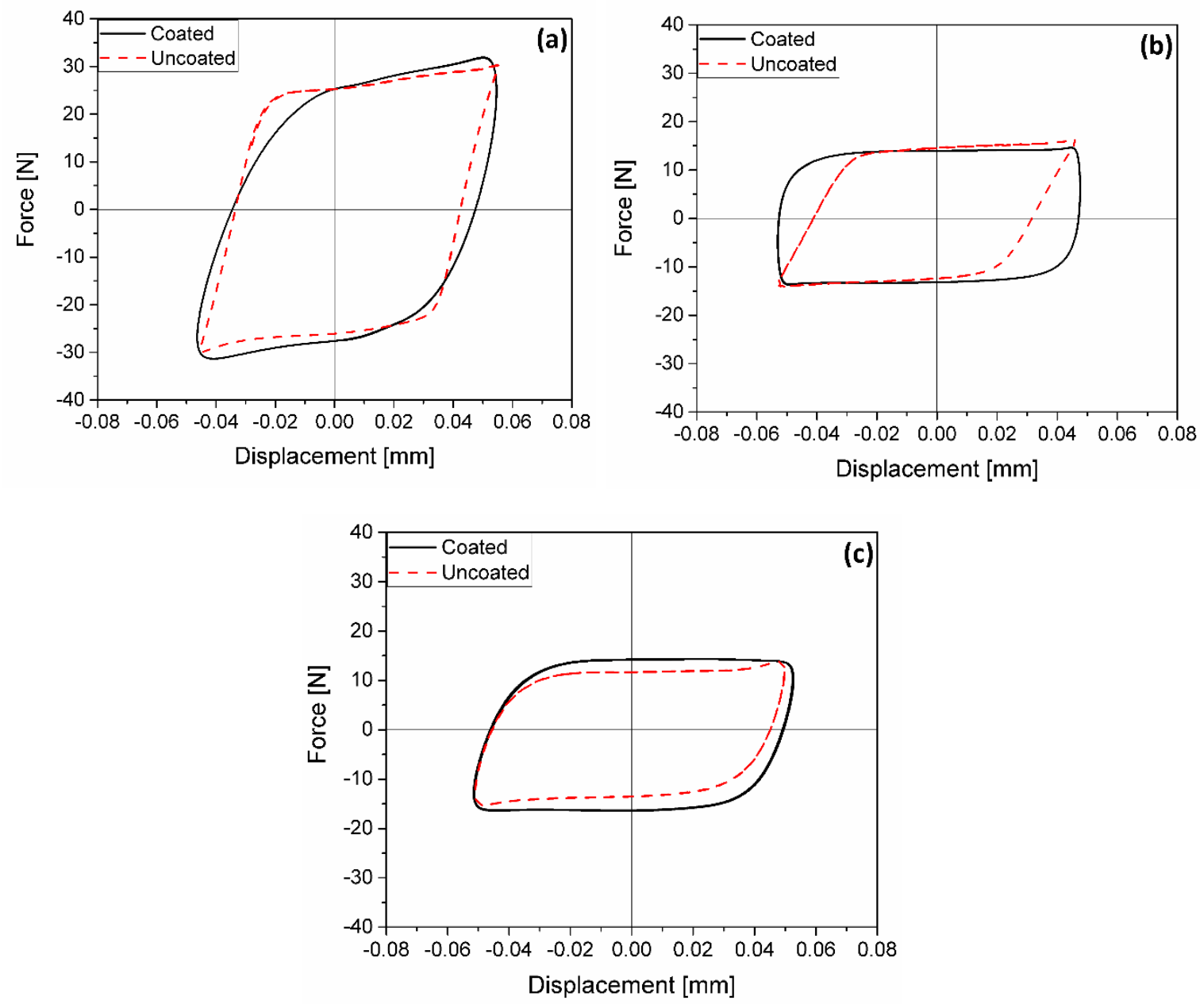

Fig.3 Hysteresis cycle of coated and uncoated friction damper experimented at (a) Room temperature (b) $300{ }^{\circ} \mathrm{C}\left(\right.$ c) $600{ }^{\circ} \mathrm{C}$ 

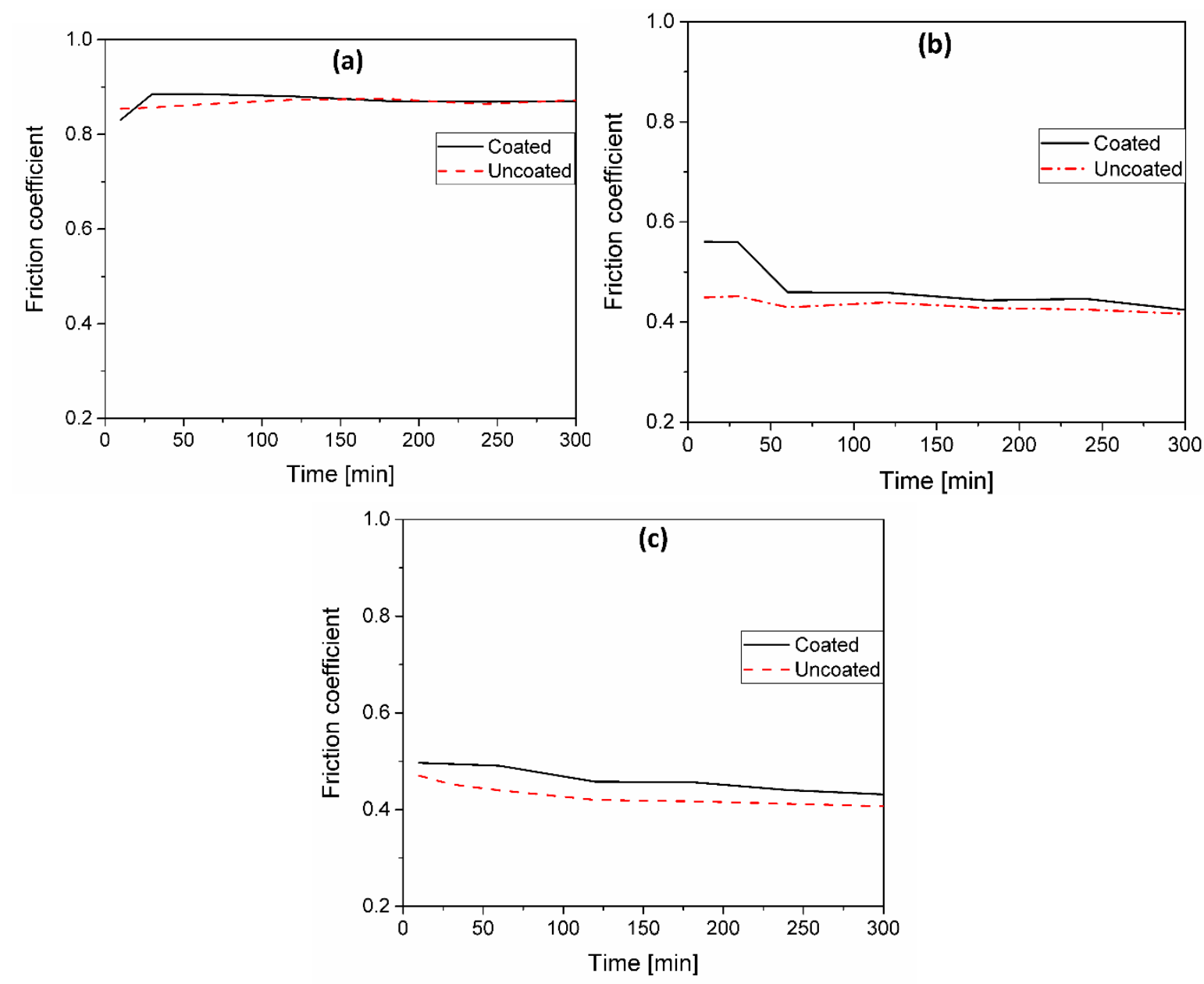

Fig.4 Variation in friction coefficient for coated and uncoated surface with time at

(a) Room temperature (b) $300{ }^{\circ} \mathrm{C}$ (c) $600{ }^{\circ} \mathrm{C}$

Coated and uncoated damaged surfaces are presented in Fig. 5-7 experimented at room temperature as well as at high temperature. From Fig. 5 it is observed that at room temperature wear on the coated surface is more in comparision to uncoated surface. On the contrary at $300{ }^{\circ} \mathrm{C}$ and $600{ }^{\circ} \mathrm{C}$ wear on coated surface is less in comparision to uncoated surface as shown in Fig. 6 and Fig. 7 respectively. The fundamental reasons to outperforming TiAlN coatings at high temperature is that at elevated temperatures oxidation resistance increased due to the formation of a protective aluminiumoxide layer at the surface. In all these three cases the relative movement of material surfaces generates wear debris particles. At room temperature wear debris particles generated are removed from the rubbing surfaces but at $300{ }^{\circ} \mathrm{C}$ debris particles are partially removed and partially retained between rubbing surfaces. However, at $600{ }^{\circ} \mathrm{C}$ debris particle completely retained between rubbing surfaces.

Fretting wear failure is quantified by maximum wear depth within damage area. Mitutoyo surface profilometer has been used to measure the surface roughness across the area of maximum damage in coated and uncoated specimen as shown in Fig. 8-10. Comparision of surface roughness elevation of wear region experimented at different temperatures is shown in Fig. 11 for flat specimen 
and cylindrical specimen. Surface roughness of $31.73 \mu \mathrm{m}$ and $32.5 \mu \mathrm{m}$ is measured in uncoated and coated flat specimen at room temperature. Whereas suface roughness of $35.86 \mu \mathrm{m}$ and $43.3 \mu \mathrm{m}$ has been measureded in uncoated and coated cylindrical specimen respectively. In addition, surface roughness of $16.7 \mu \mathrm{m}$ and $10.5 \mu \mathrm{m}$ is measured at $300{ }^{\circ} \mathrm{C}$ for uncoated and coated flat specimen. However, for the cylindrical uncoated and coated specimen these values are noted as $16.05 \mu \mathrm{m}$ and 7.5 $\mu \mathrm{m}$ respectively. Surface roughness of $30.5 \mu \mathrm{m}$ and $17.5 \mu \mathrm{m}$ is measured in flat and cylindrical uncoated specimen at $600^{\circ} \mathrm{C}$. However, in coated specimen there is no measure sign of wear. Hence, it is concluded that wear rate in coated specimen is less in comparison to uncoated specimen at high temperature.

A Hitech S-4200 scanning electron microscopy (SEM) has been used to see the wear scar of damage surfaces as shown in the Fig. 12-14. At room temperature shown in Fig. 12, the uncoated specimen shows adhesive wear behavior whereas the coated specimen shows abrasive wear behavior. At room temperature the uncoated specimen shows mild adhesive wear where the material from opposing specimen has been transferred. At higher temperature $\left(300^{\circ} \mathrm{C}\right.$ in Fig. $\left.13 \& 600^{\circ} \mathrm{C} \mathrm{Fig.} \mathrm{14}\right)$, the uncoated specimen experiences severe wear (both adhesive and abrasive wear). The uncoated specimen has severe surface asperities and the wear surface has two distinct regions: a region of high asperities with material removed by abrasion, and the region with smoothened contact surface showing the material flow lines along the wear direction. The material flow may be due to the enhanced plastic flow at high temperature and indicate the adhesive wear occurrences. In addition, there were micro grooves and deep groves on the smoothened contact surface indicating abrasive wear behavior. The transition from adhesive to abrasive wear could be because of the stain hardening of the material due to plastic deformation.

The coated specimen mostly shows the abrasive wear behavior at room temperature with few crack nucleation and initiation occurances. However, a little delamination of the coating layer on the cylindrical specimen at few places is observed. At $300^{\circ} \mathrm{C}$ the coated flat specimen shows the plastic flow with smoothened contact surface upon which there are evident wear lines/patterns (mixed adhesive and abrasive wear behavior). At $600^{\circ} \mathrm{C}$ the surface asperities are observed on both coated flat and cylindrical specimens. Few material asperities from flat specimen appeard as welded on to the cylindrical specimens. 

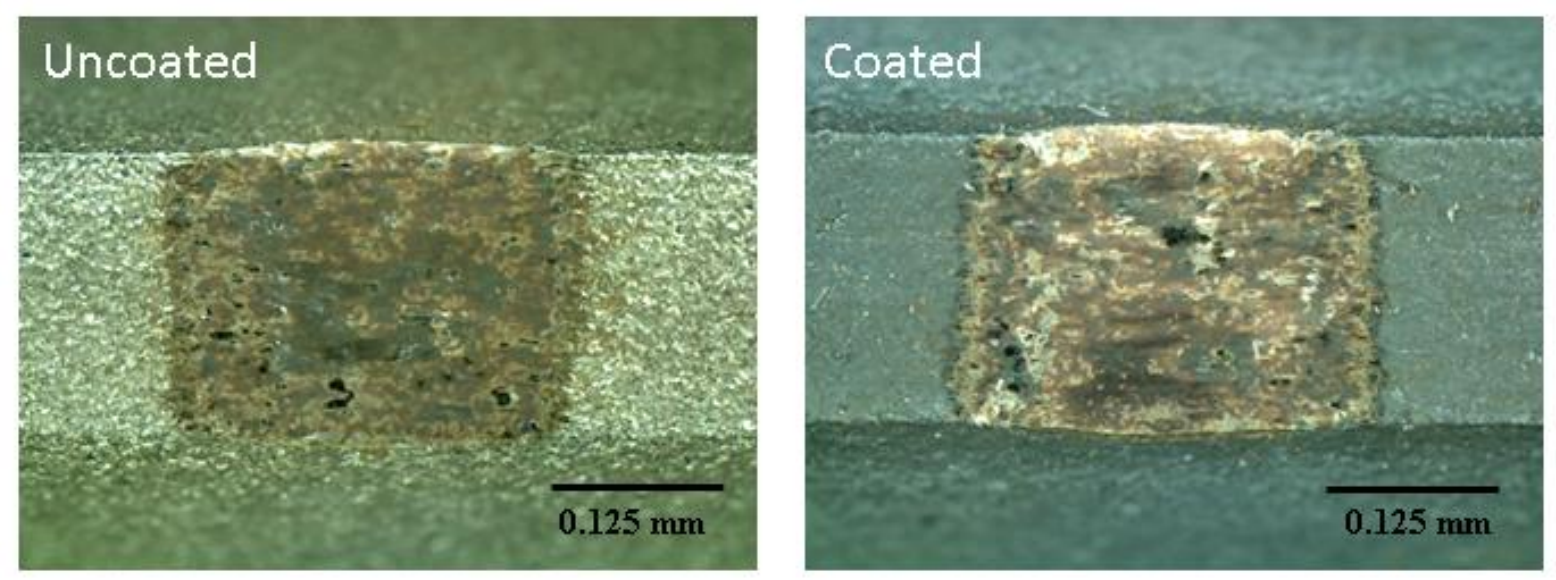

(a)
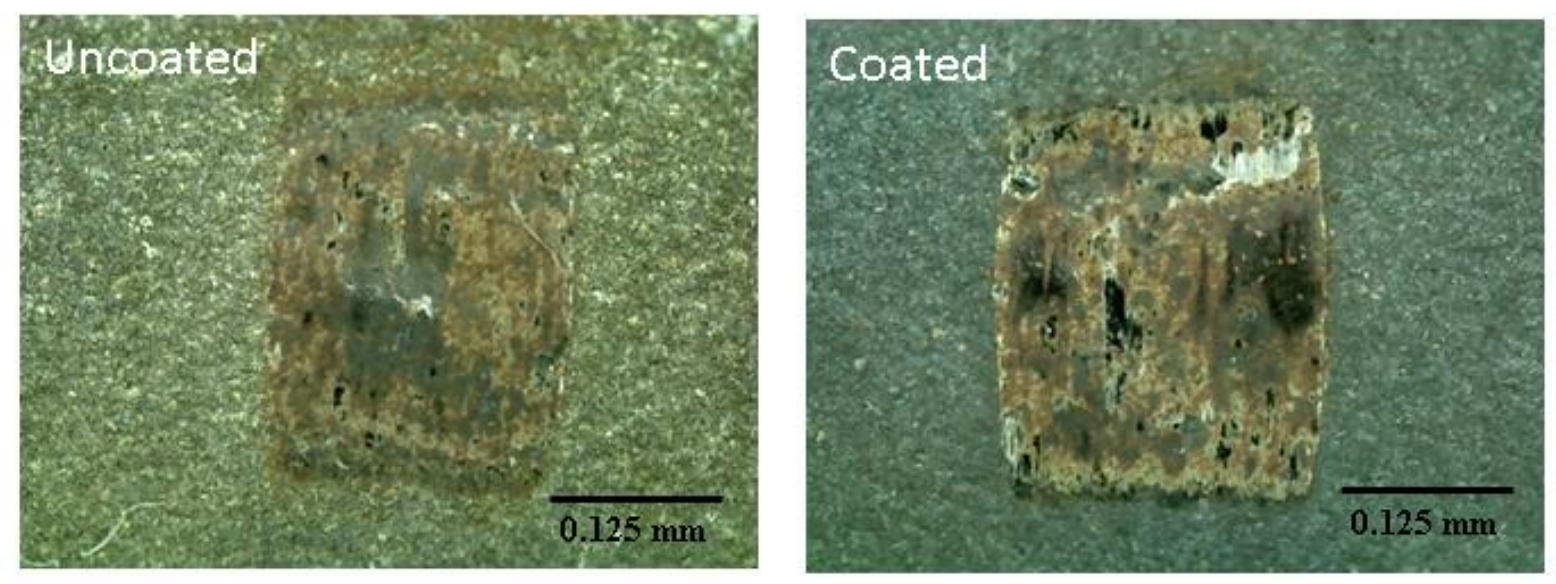

(b)

Fig.5 Optical microscope images of wear surface experimented at room temperature (a) Flat (b) Cylindrical specimen 

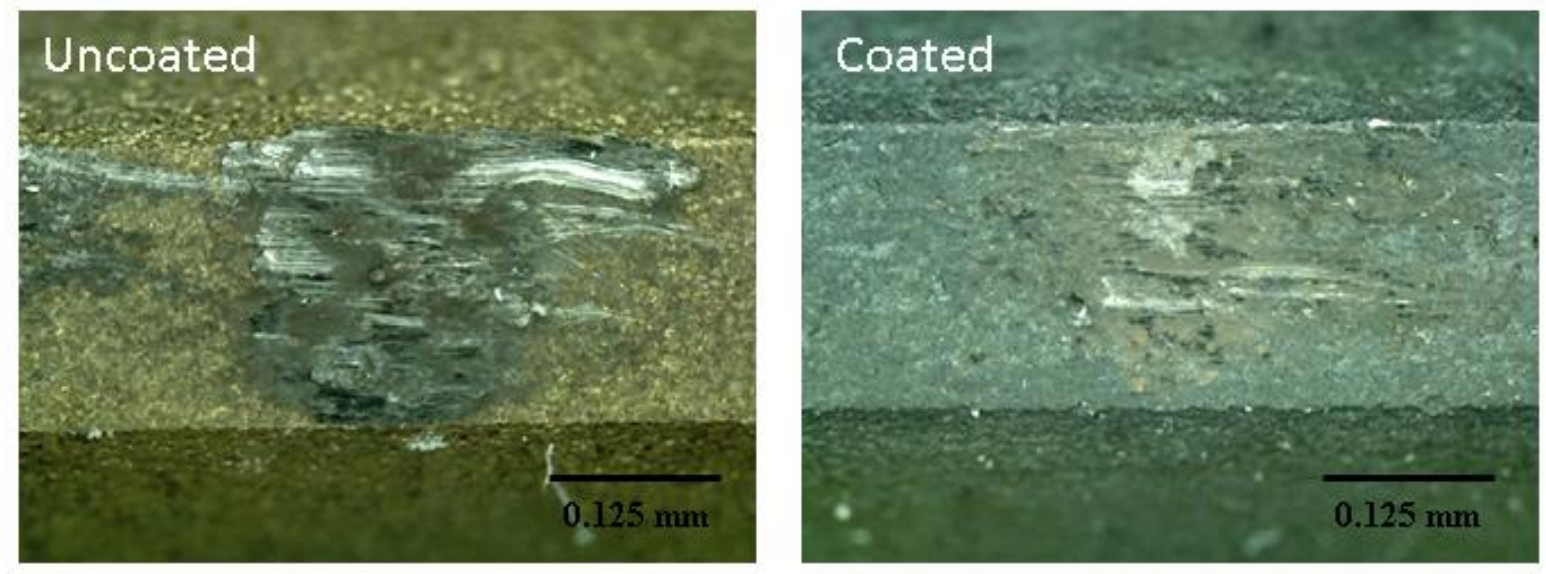

(a)
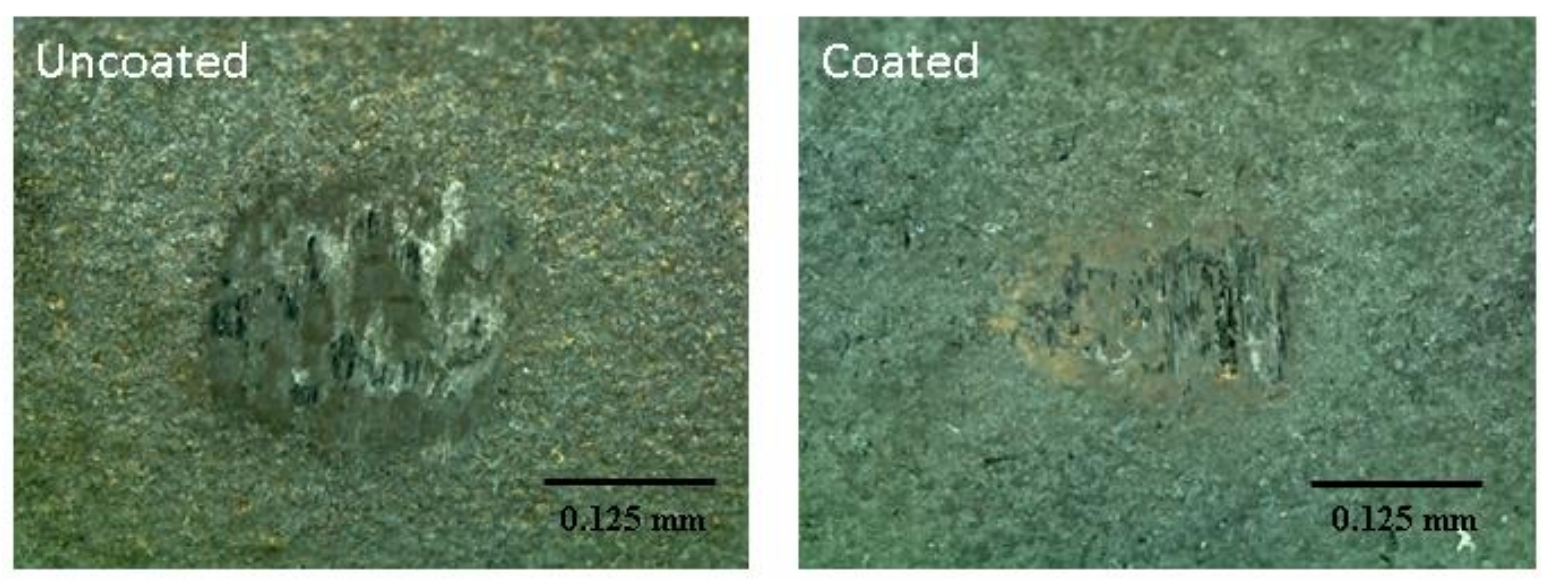

(b)

Fig.6. Optical microscope images of wear surface experimented at $300^{\circ} \mathrm{C}$ (a) Flat

(b) Cylindrical specimen 

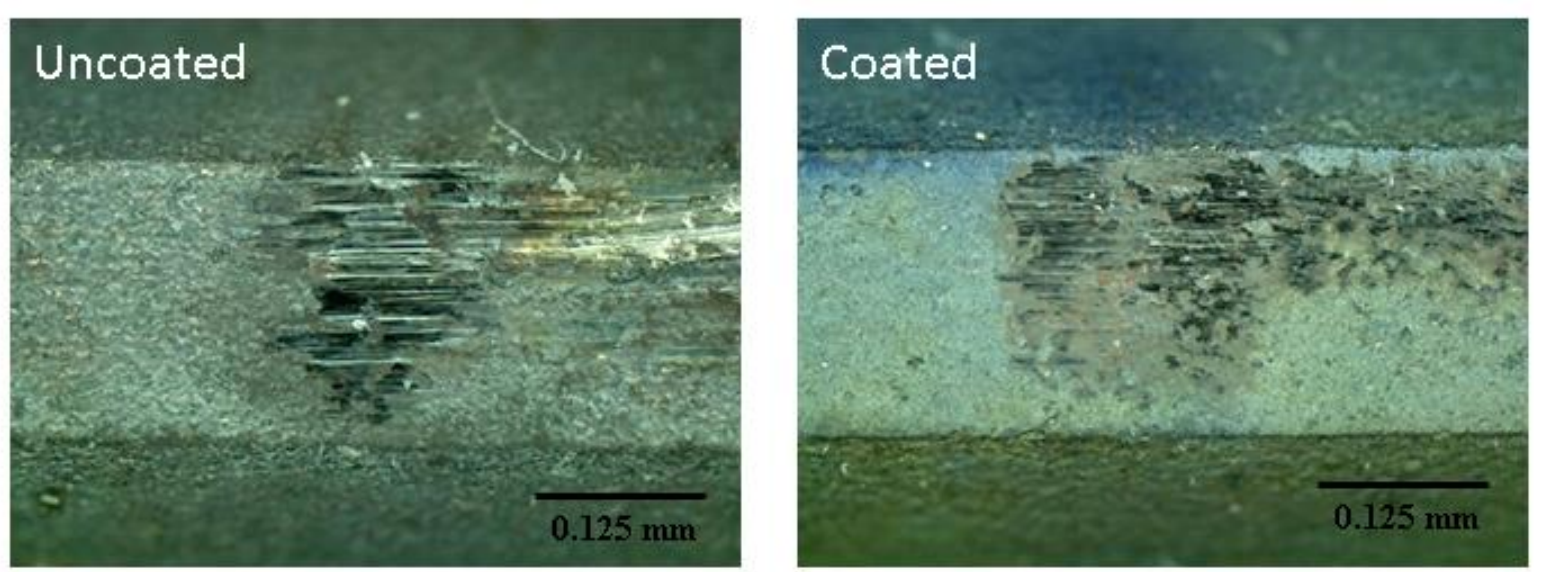

(a)
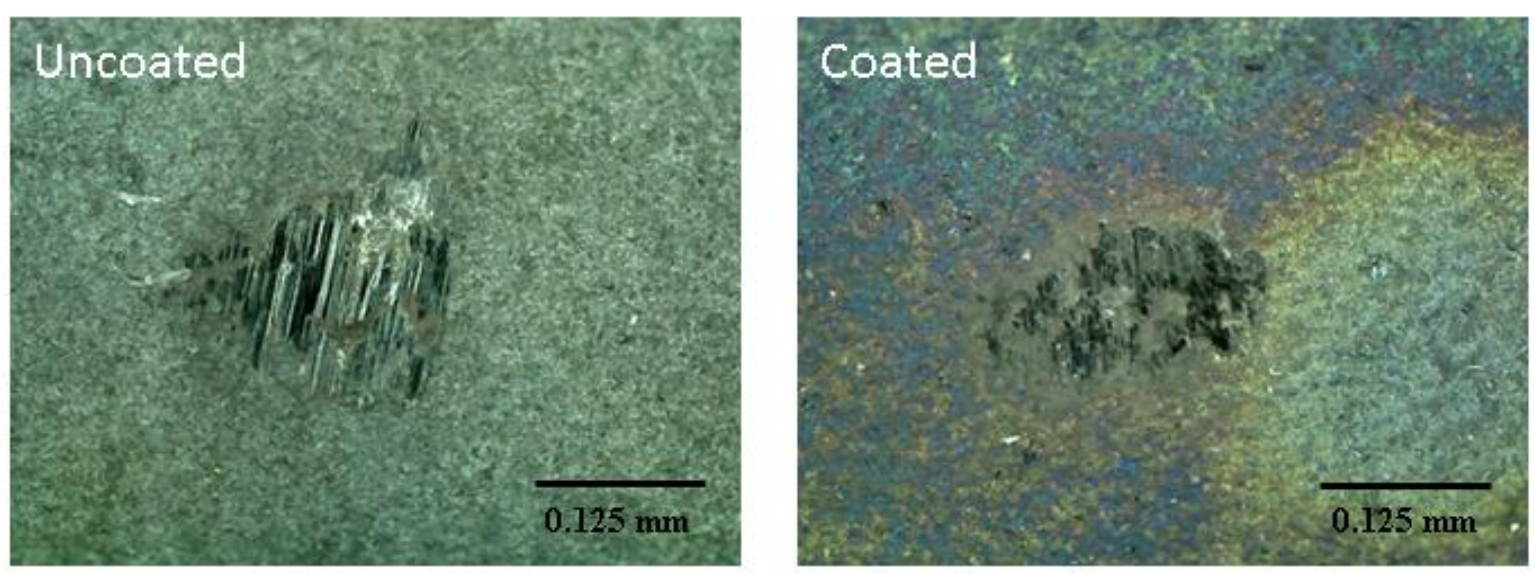

(b)

Fig.7. Optical microscope images of wear surface experimented at $600{ }^{\circ} \mathrm{C}$ (a) Flat

(b) Cylindrical specimen 

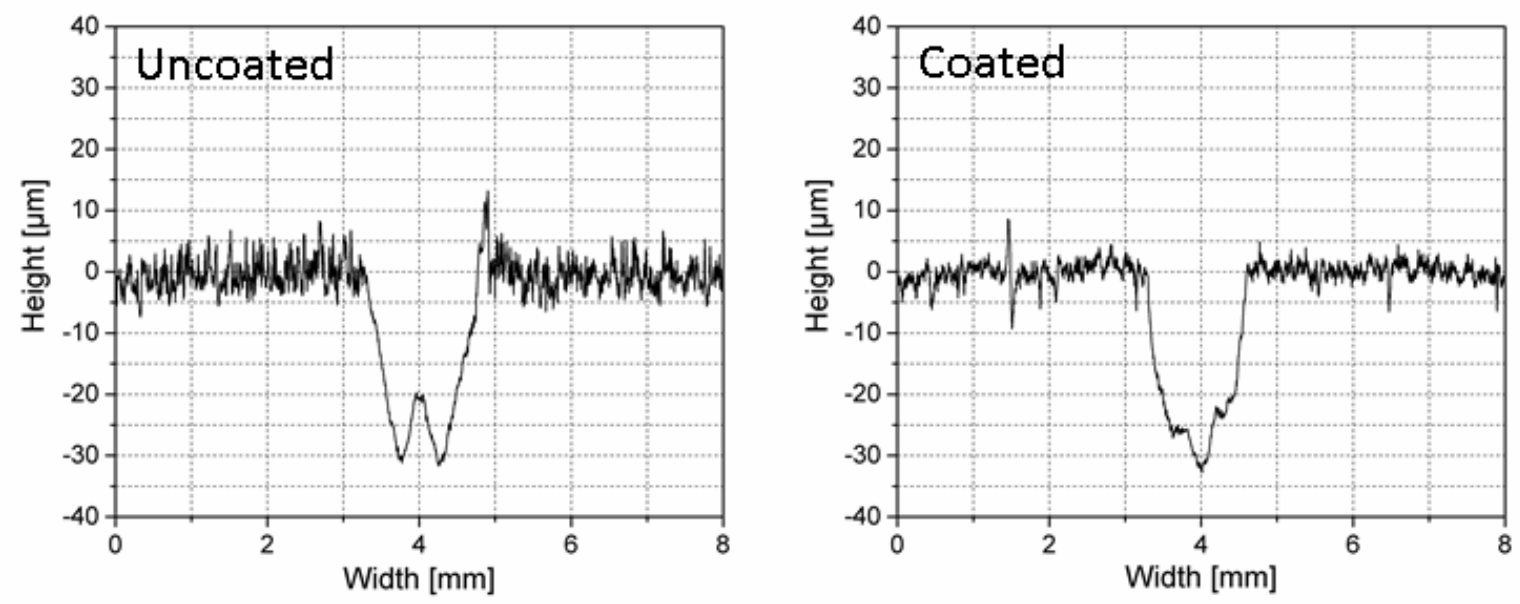

(a)
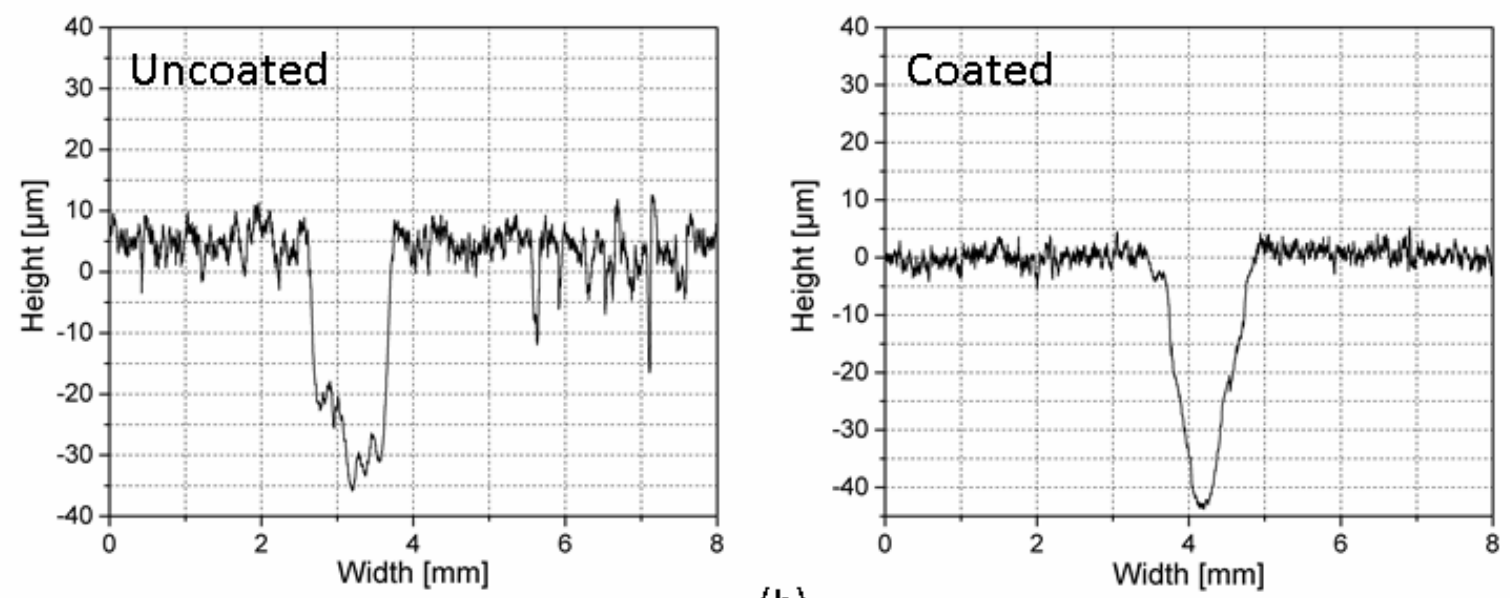

(b)

Fig.8. Surface roughness profile of damage surface experimented at room temperature (a) Flat (b) cylindrical specimen 

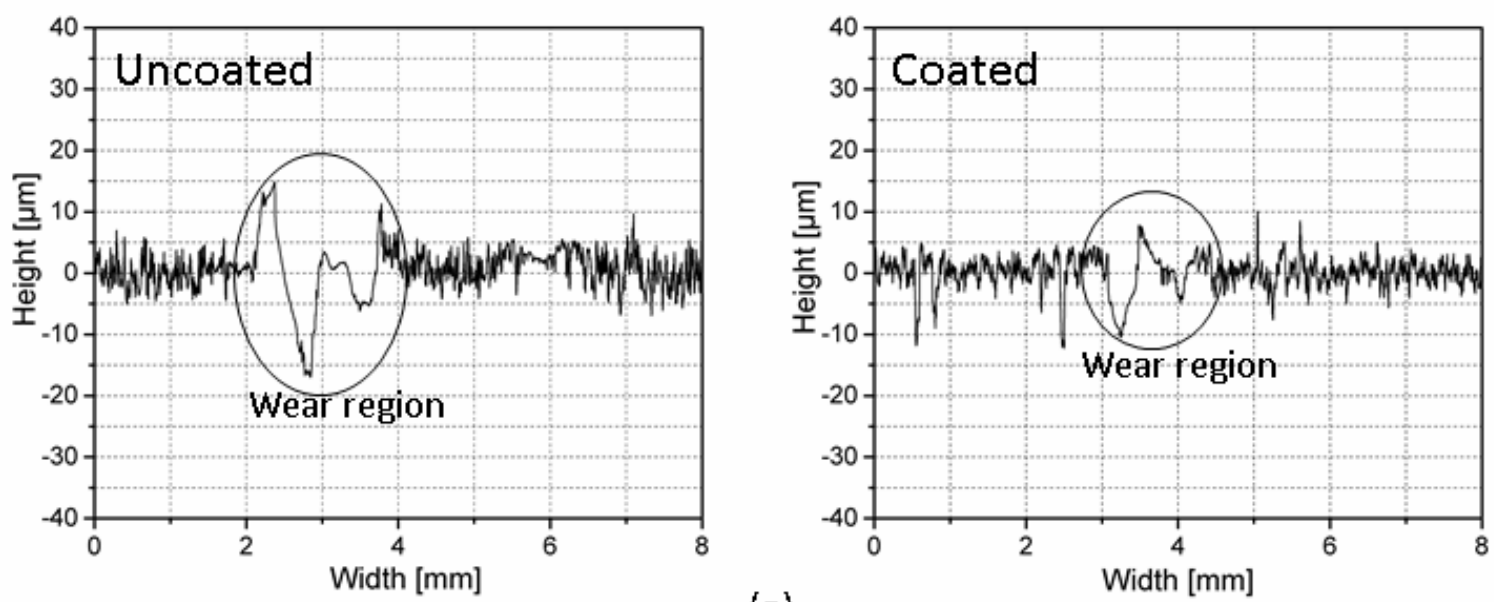

(a)
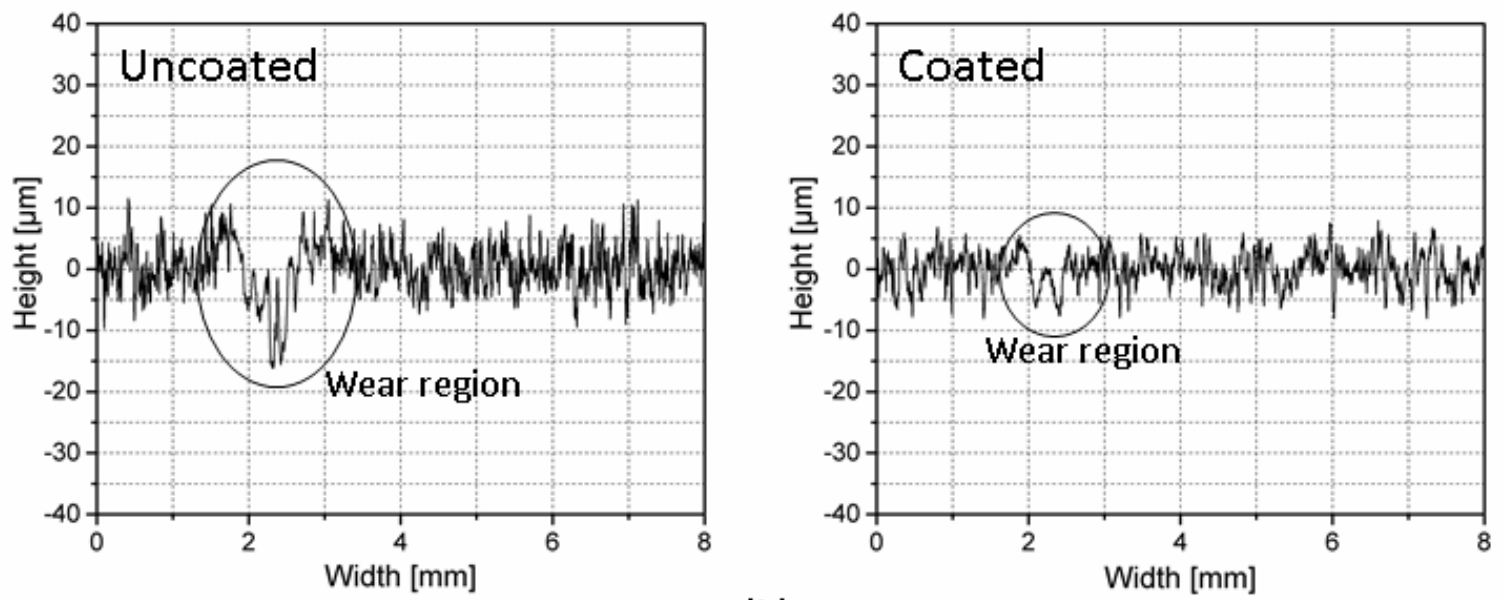

(b)

Fig.9. Surface roughness profile of damage surface experimented at $300^{\circ} \mathrm{C}$ (a) Flat (b) cylindrical specimen 

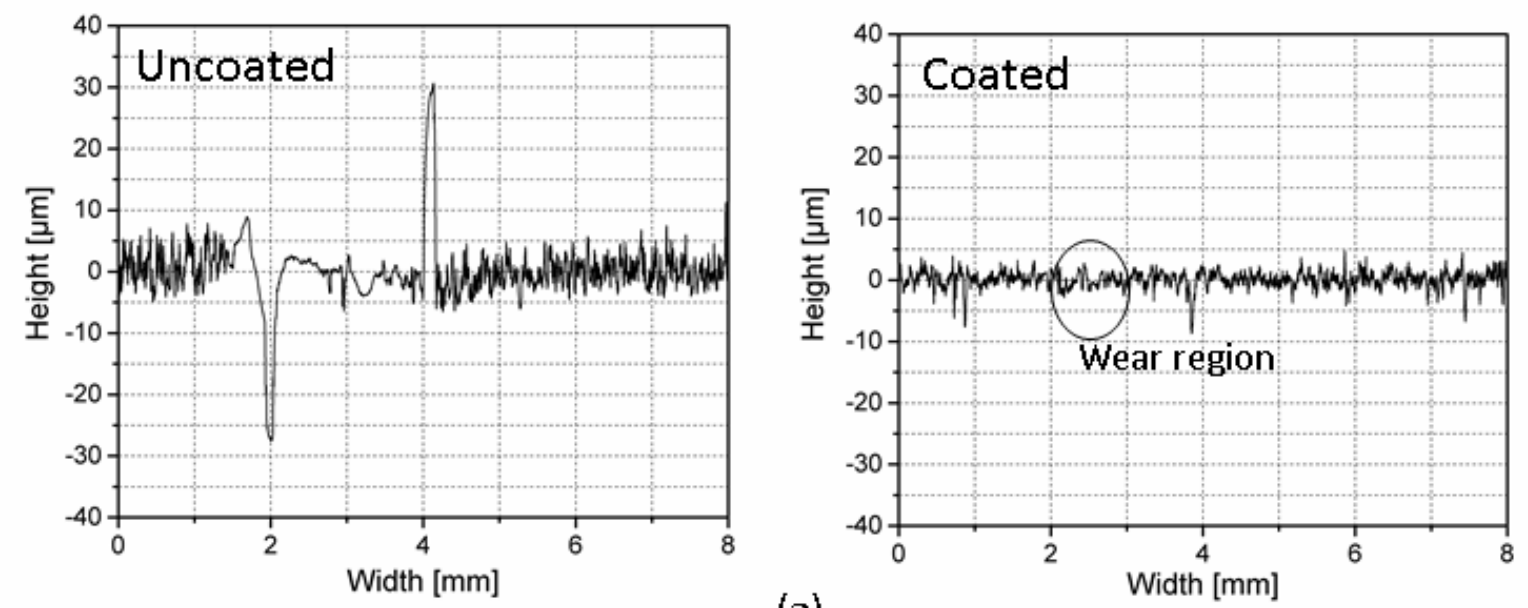

(a)
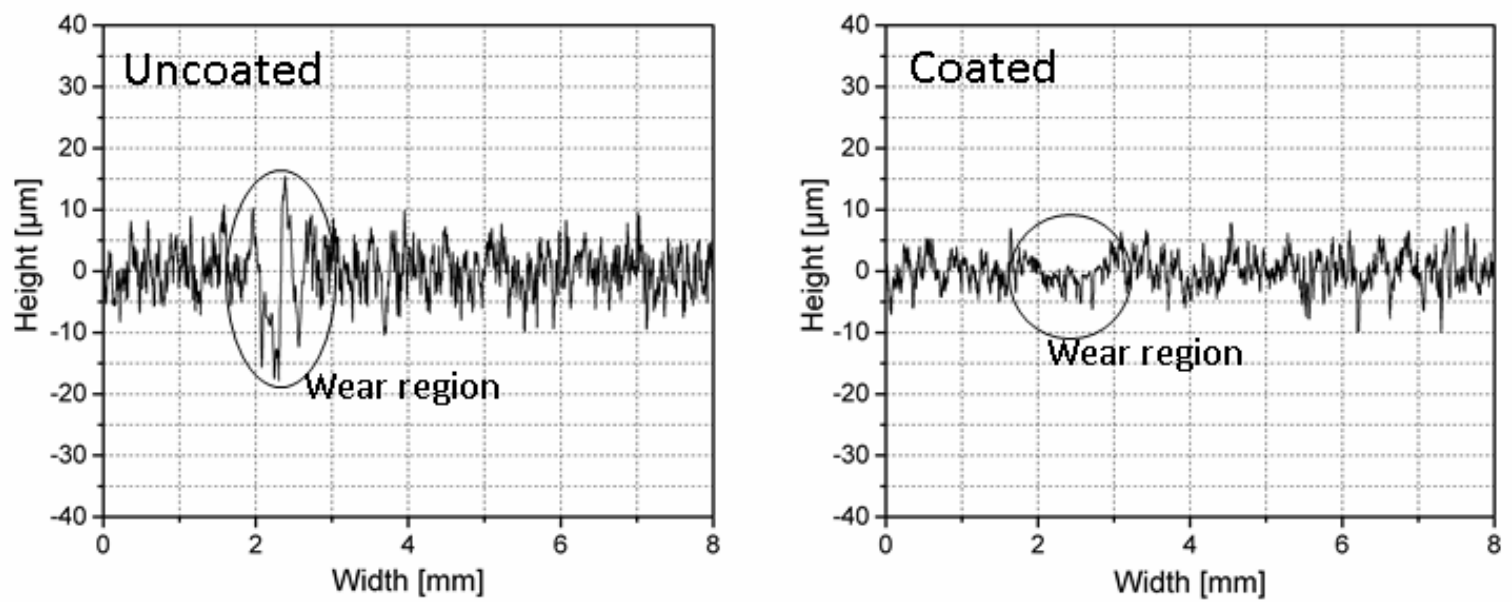

(b)

Fig.10. Surface roughness profile of damage surface experimented at $600{ }^{\circ} \mathrm{C}$ (a) Flat (b) cylindrical specimen 


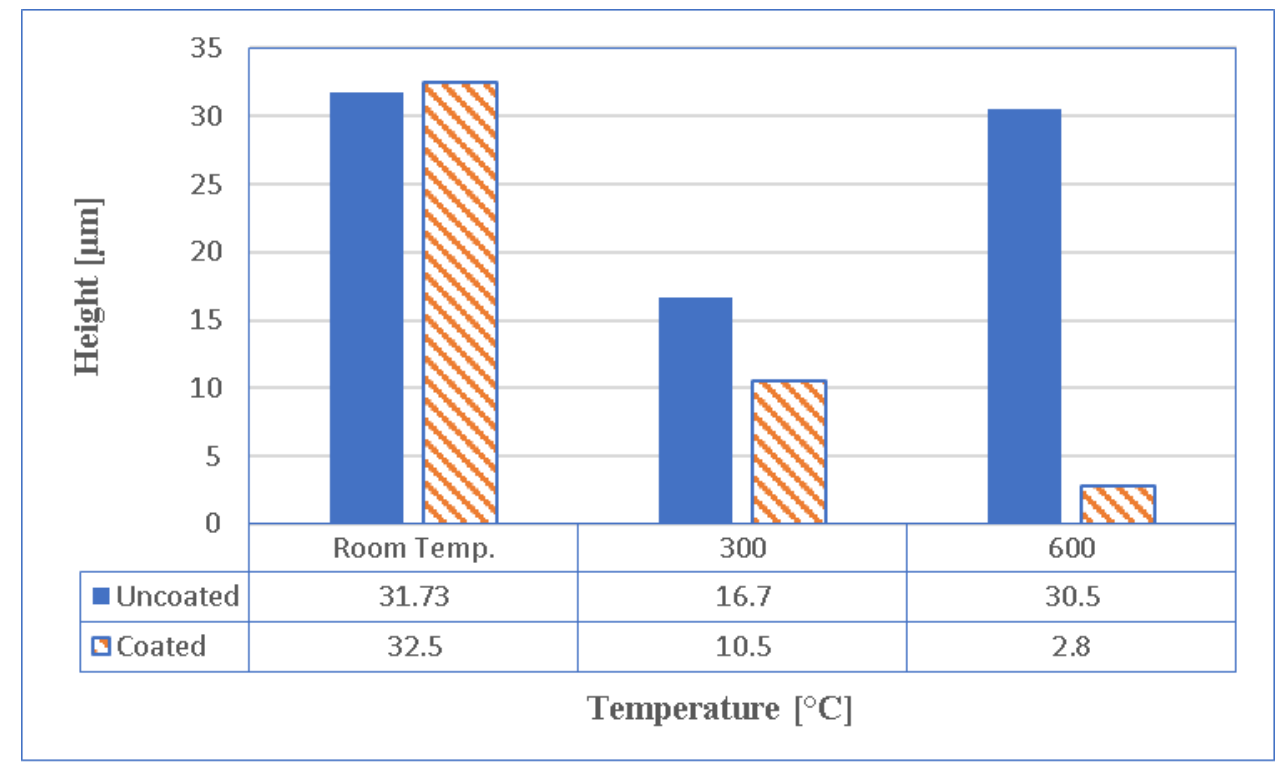

(a)

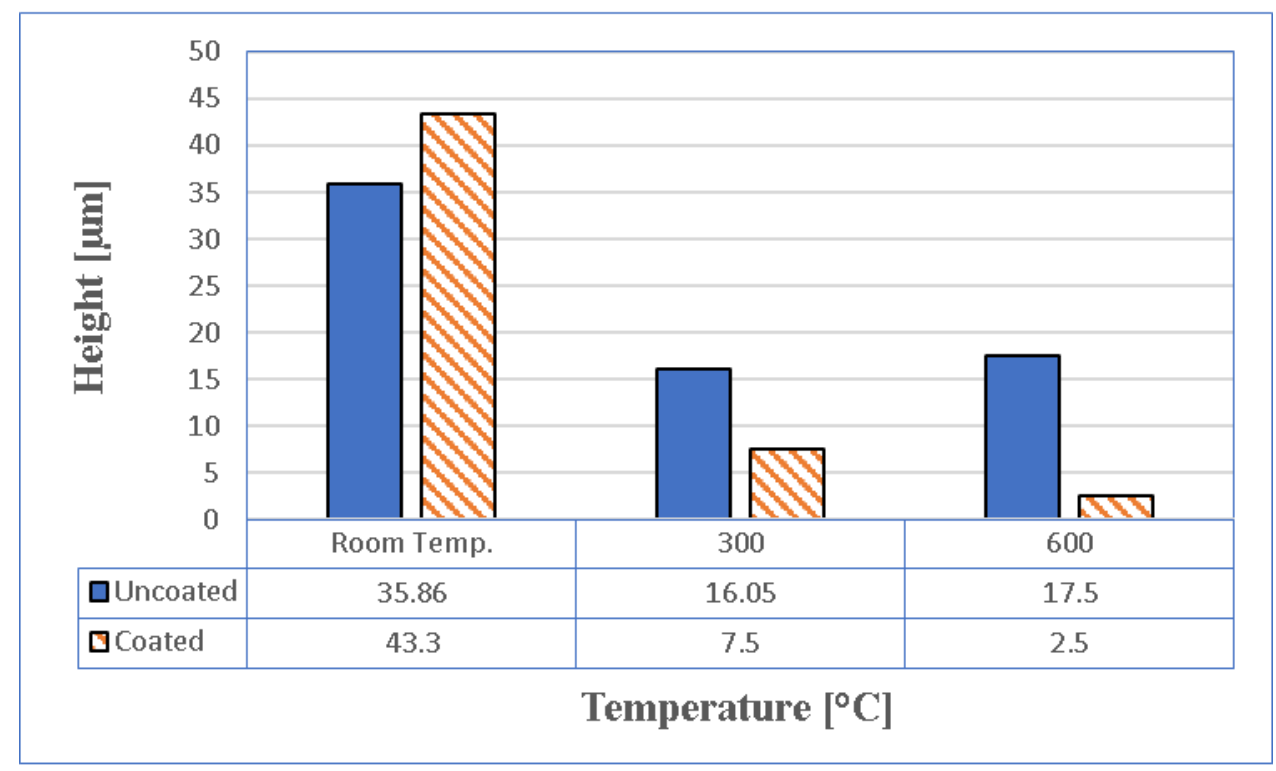

(b)

Fig.11. Comparision of Surface roughness elevation of wear region at different temperature (a) Flat (b) cylindrical specimen 

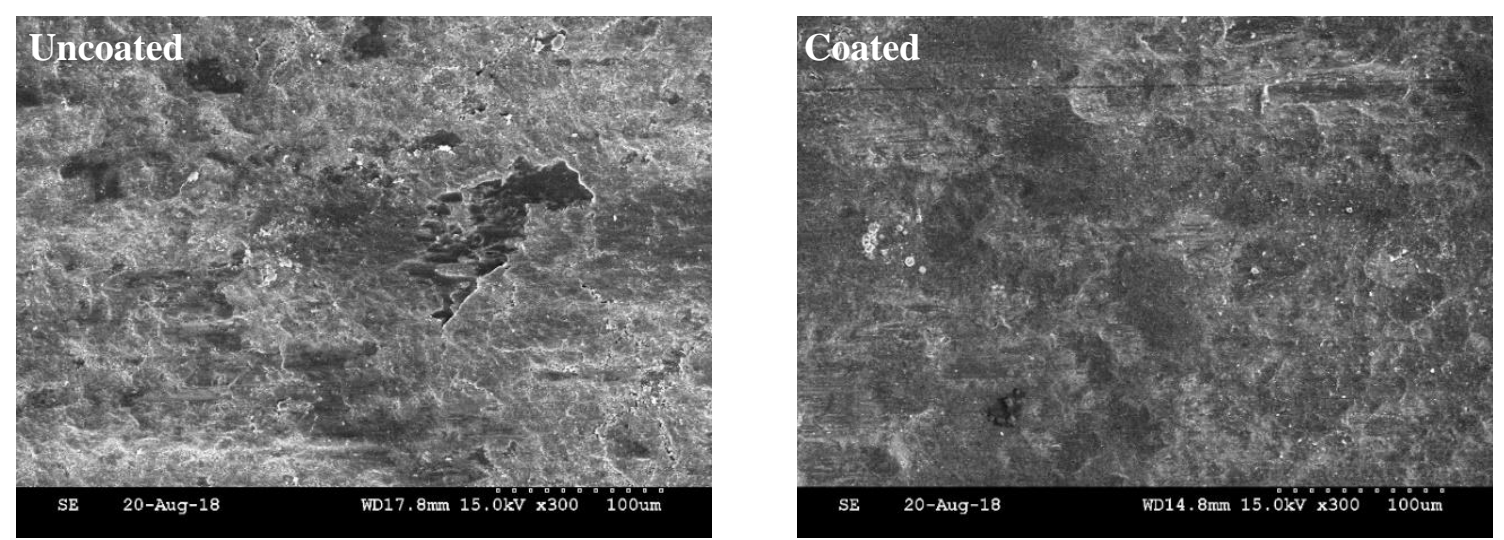

(a)
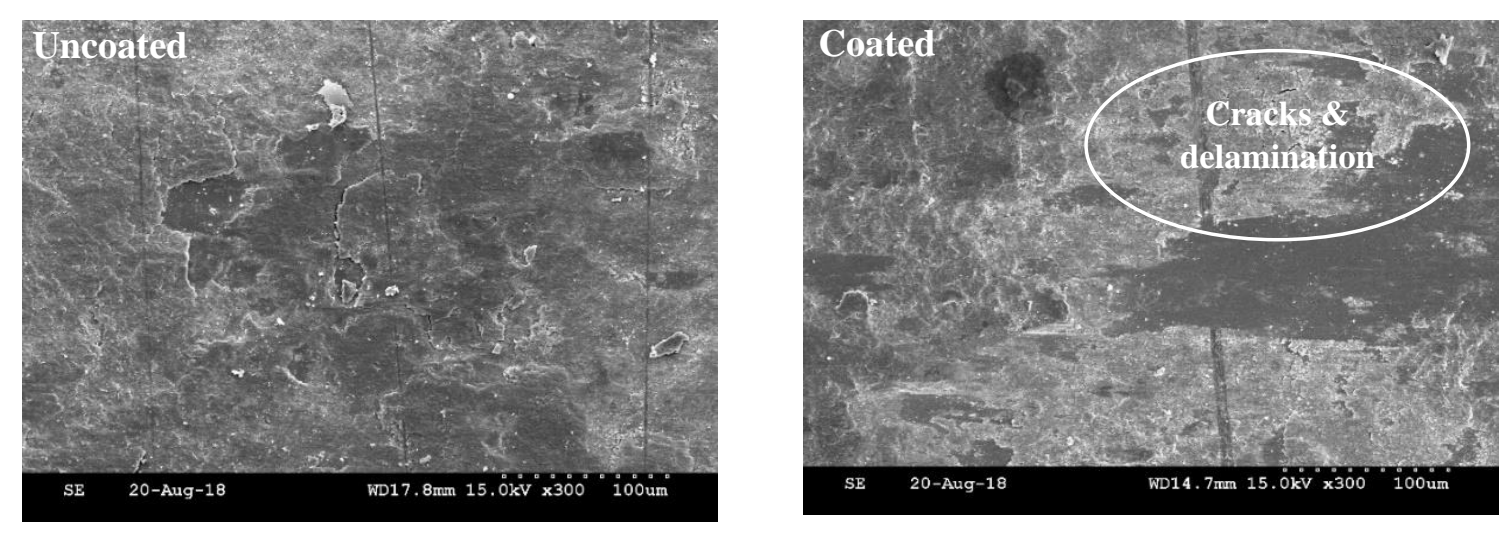

(b)

Fig.12. SEM images of damage surface experimented at room temperature (a) Flat (b) cylindrical specimen 

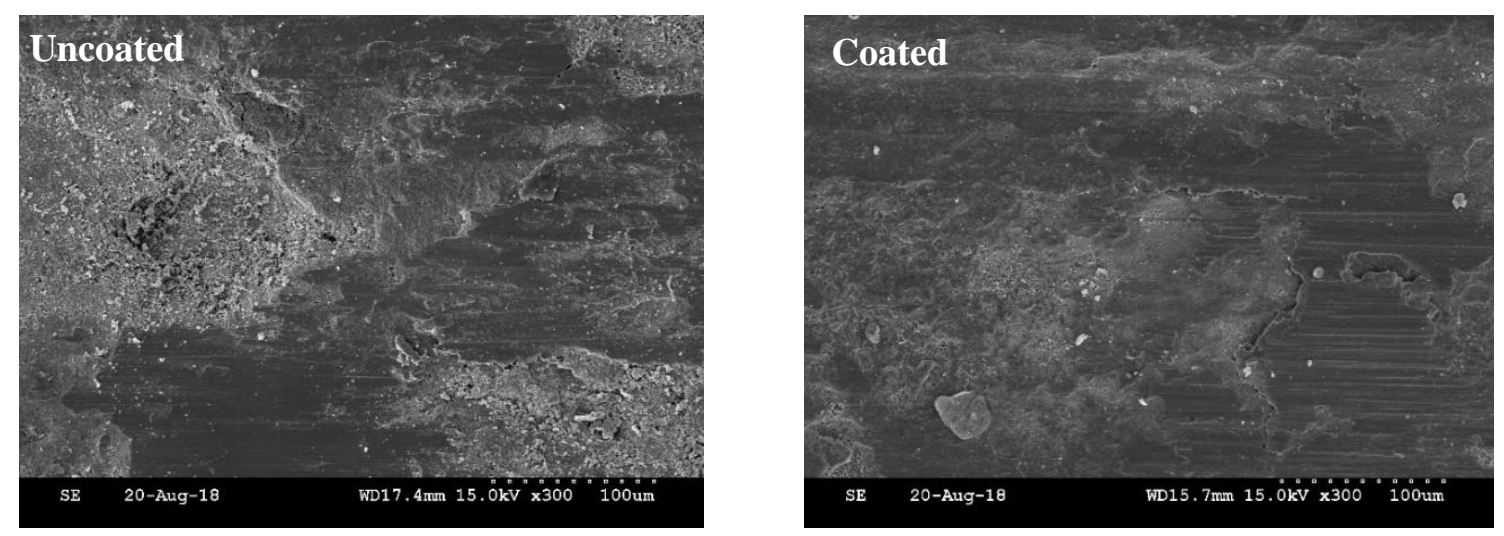

(a)
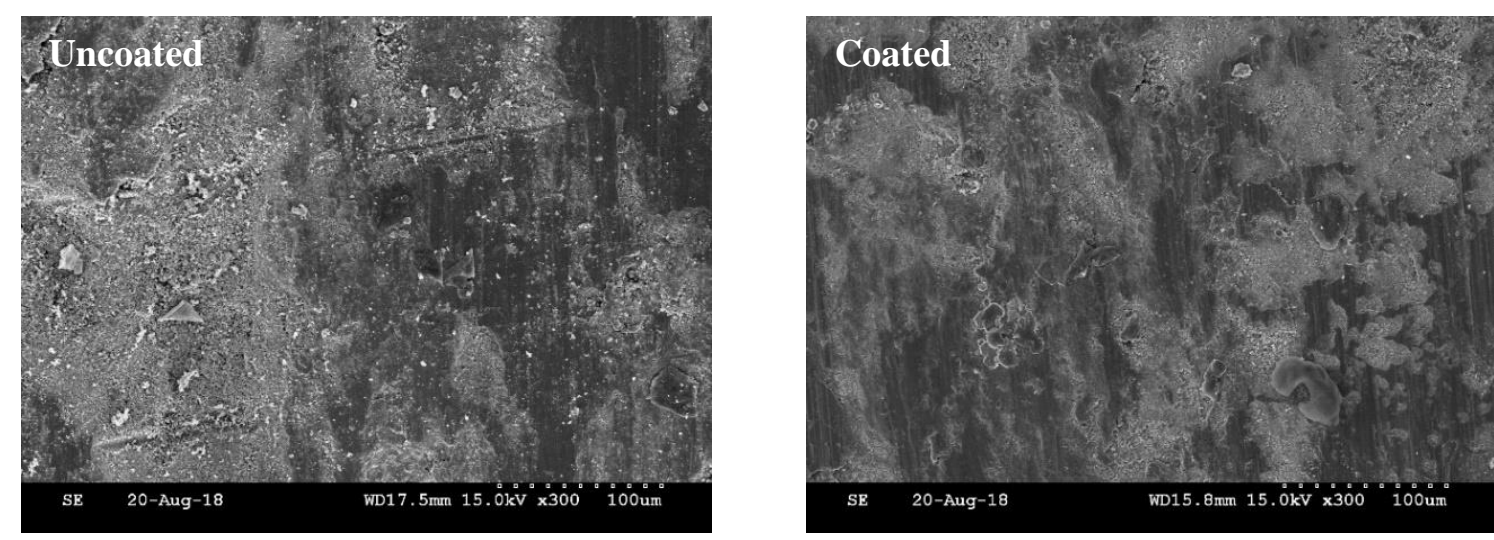

(b)

Fig.13. SEM images of damaged surface experimented at $300^{\circ} \mathrm{C}$ (a) Flat specimen (b) cylindrical specimen 

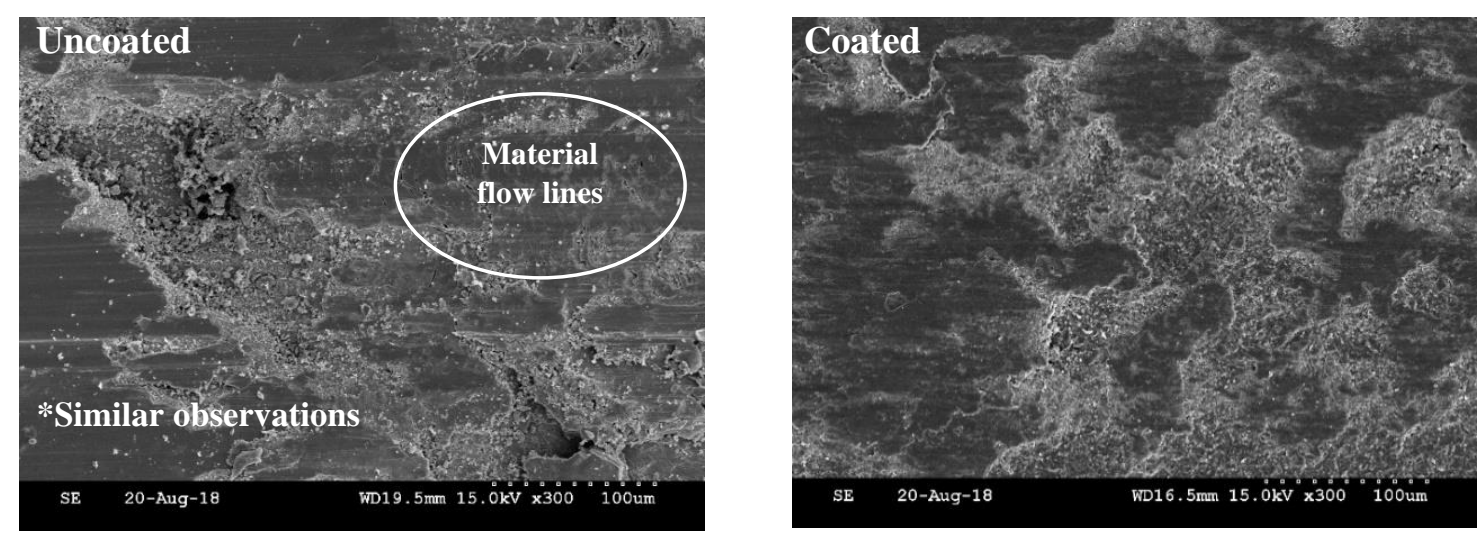

(a)
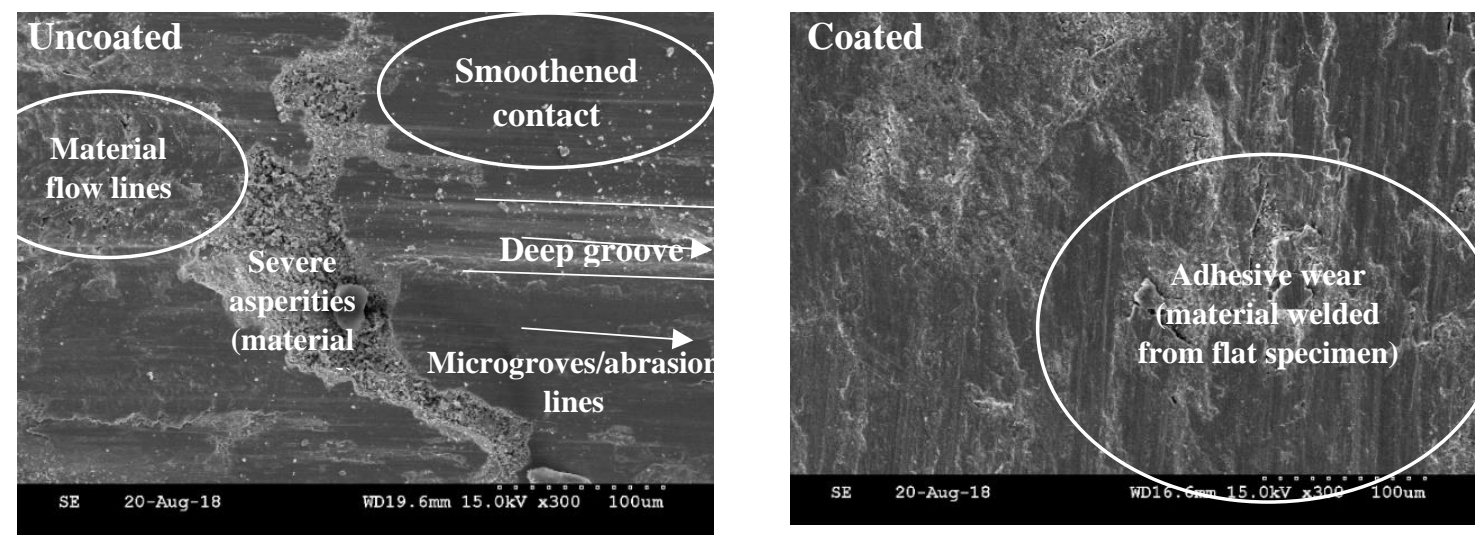

(b)

Fig.14. SEM images of damage surface experimented at $600^{\circ} \mathrm{C}$ (a) Flat specimen (b) cylindrical specimen 
Table.1: Experimental parameters

\begin{tabular}{|c|c|}
\hline Normal load & $30.2 \mathrm{~N}$ \\
\hline Amplitude of slip & $\pm 50 \mu \mathrm{m}$ \\
\hline Frequency & $20 \mathrm{~Hz}$ \\
\hline Temperature & $\mathrm{RT}, 300^{\circ} \mathrm{C}, 600{ }^{\circ} \mathrm{C}$ \\
\hline Test duration & $5 \mathrm{hrs}$ \\
\hline Specimen material & Stainless steel \\
\hline Specimens contact type & Line \\
\hline Coating thickness & $4-5 \mu \mathrm{m}$ \\
\hline Specimen diameter & $12 \mathrm{~mm}$ \\
\hline
\end{tabular}

\section{CONCLUSION}

In this work, Nitride based physical vapor deposition (PVD) coating AlTiN material has been used to investigate the effect of coating on the performance of friction damper. With the use of AlTiN coating materials the friction coefficient in coated and uncoated specimen is almost same at room temperature, but at high temperature value of friction coefficient in coated specimen is more in comparison to uncoated specimen. As friction between the contact surfaces is the key point of the vibration energy dissipation. Therefore the damping capacity of coated and uncoated friction damper is almost same at room temperature. However, at high temperatures $\left(300{ }^{\circ} \mathrm{C} \& 600{ }^{\circ} \mathrm{C}\right)$ damping capacity of coated friction damper is better than the uncoated friction damper. Also, AlTiN coating material is very effective to reduce the fretting wear in friction damper at high temperature but not at room temperature. This is remarkable evidence of the improved performance of friction dampers at elevated temperature. The uncoated specimen shows the adhesive wear behavior whereas the coated specimen show abrasive wear behavior at room temperature. On the other hand, the uncoated specimen experiences severe wear (both adhesive and abrasive wear) whereas coated material shows few plastic flow evidences and few weld spots with asperities at elevated temperatures.

Fretting-wear depends on many system parameters such as excitation amplitude, excitation frequency, normal load at contact surface, material of coating and the temperature. It will be interesting to investigate the combined effects of different system parameters on the fretting wear for future studies.

\section{REFRENCES}

[1] K. Popp, L. Panning, and W. Sextro, "Vibration Damping by Friction Forces: Theory and Applications," Modal Anal., vol. 9, no. 3-4, pp. 419-448, 2003.

[2] S. Zucca, D. Di Maio, and D. J. Ewins, "Measuring the performance of underplatform dampers for turbine blades by rotating laser Doppler vibrometer," Mech. Syst. Signal Process., vol. 32, pp. 269-281, 2012.

[3] J. Wu, R. Yuan, Z. He, D. Zhang, and Y. Xie, "Experimental study on dry friction damping characteristics of the steam turbine blade material with nonconforming 
contacts,” Adv. Mater. Sci. Eng., vol. 2015, 2015.

[4] L. Salles, L. Blanc, F. Thouverez, and A. M. Gouskov, "Dynamic analysis of frettingwear in friction contact interfaces," Int. J. Solids Struct., vol. 48, no. 10, pp. 1513-1524, 2011.

[5] H. Dong, Tribological properties of titanium-based alloys. Surface Engineering of Light Alloys: Aluminium, Magnesium and Titanium Alloys. 58-80. 10.1533/9781845699451.1.58.

[6] A. Sinha and J. H. Griffin, "Effects of Static Friction on the Forced Response of Fictionally Damped Turbine Blades," vol. 1, no. January 1984, pp. 1-5, 1984.

[7] J. H. Griffin and A. Sinha, "The Interaction between Mistuning and Friction in the Forced Response of Bladed Disk Assemblies," J. Eng. Gas Turbines Power, vol. 107, no. 1, pp. 205-211, 1985.

[8] A. Sinha and J. H. Griffin, "Friction Damping of Resonant Stresses in Gas Turbine Engine Airfoils,” J. Eng. Power, vol. 102, no. 2, pp. 329-333, 1982.

[9] M. Lavella and D. Botto, "Fretting wear characterization by point contact of nickel superalloy interfaces," Wear, vol. 271, no. 9-10, pp. 1543-1551, 2011.

[10] D. Botto and M. Lavella, "High temperature tribological study of cobalt-based coatings reinforced with different percentages of alumina," Wear, vol. 318, no. 1-2, pp. 89-97, 2014.

[11] A. Liu, J. Deng, H. Cui, Y. Chen, and J. Zhao, "Friction and wear properties of TiN, TiAlN, AlTiN and CrAIN PVD nitride coatings," Int. J. Refract. Met. Hard Mater., vol. 31, pp. 82-88, 2012.

[12] S. Filippi, E. B. Rodrigues, and M. M. Gola, "Experimental characterization of contact hysteresis at high temperatures," ASME. Turbo Expo: Power for Land, Sea, and Air, Volume 5: Marine; Microturbines and Small Turbomachinery; Oil and Gas Applications; Structures and Dynamics, Parts A and B ():893-902. doi:10.1115/GT2006-90757.

[13] C. W. Schwingshackl, E. P. Petrov, and D. J. Ewins, "Measured and estimated friction interface parameters in a nonlinear dynamic analysis," Mech. Syst. Signal Process., vol. 28, no. April 2012, pp. 574-584, 2012.

[14] M. Lavella, D. Botto, and M. M. Gola, "Design of a high-precision, flat-on-flat fretting test apparatus with high temperature capability," Wear, vol. 302, no. 1-2, pp. 10731081, 2013. 